\title{
BMJ Open Direct inpatient burden caused by foot-related conditions: a multisite point-prevalence study
}

\author{
Peter A Lazzarini, ${ }^{1,2,3,4,5}$ Sheree E Hurn, ${ }^{1,2}$ Suzanne S Kuys, ${ }^{3,6}$ Maarten C Kamp, ${ }^{1}$ \\ Vanessa Ng, ${ }^{1,3}$ Courtney Thomas, ${ }^{7}$ Scott Jen, ${ }^{8}$ Ewan M Kinnear, ${ }^{3,4}$ \\ Michael C d'Emden, ${ }^{9,10}$ Lloyd Reed $^{1,2}$
}

To cite: Lazzarini PA, Hurn SE, Kuys SS, et al. Direct inpatient burden caused by foot-related conditions: a multisite pointprevalence study. BMJ Open 2016:6:e010811.

doi:10.1136/bmjopen-2015010811

- Prepublication history and additional material is available. To view please visit the journal (http://dx.doi.org/ 10.1136/bmjopen-2015010811).

Received 11 December 2015 Revised 5 May 2016 Accepted 24 May 2016

CrossMark

For numbered affiliations see end of article.

Correspondence to Peter A Lazzarini; Peter. Lazzarini@health.qld.gov.au

\section{ABSTRACT}

Objective: The aims of this point-prevalence study were to investigate a representative inpatient population to determine the prevalence of people admitted to hospital for the reason of a foot-related condition, and identify associated independent factors.

Methods: Participants were adult inpatients in 5 different representative hospitals, admitted for any reason on the day of data collection. Maternity, mental health and cognitively impaired inpatients were excluded. Participants were surveyed on a range of self-reported demographic, social determinant, medical history, foot disease history, self-care, footwear, past foot treatment prior to hospitalisation and reason for admission variables. Physical examinations were performed to clinically diagnose a range of foot disease and foot risk factor variables. Independent factors associated with being admitted to hospital for the primary or secondary reason of a foot-related condition were analysed using multivariate logistic regression.

Results: Overall, 733 participants were included; mean (SD) age 62 (19) years, male $55.8 \%$. Footrelated conditions were the primary reason for admission in 54 participants $(7.4 \%(95 \% \mathrm{Cl} 5.7 \%$ to $9.5 \%)) ; 36$ for foot disease (4.9\%), 15 foot trauma $(2.1 \%)$. Being admitted for the primary reason of a foot-related condition was independently associated with foot infection, critical peripheral arterial disease, foot trauma and past foot treatment by a general practitioner and surgeon $(p<0.01)$. Footrelated conditions were a secondary reason for admission in 28 participants (3.8\% (2.6\% to $5.6 \%)$ ), and were independently associated with diabetes and current foot ulcer $(p<0.01)$.

Conclusions: This study, the first in a representative inpatient population, suggests the direct inpatient burden caused by foot-related conditions is significantly higher than previously appreciated. Findings indicate 1 in every 13 inpatients was primarily admitted because of a footrelated condition with most due to foot disease or foot trauma. Future strategies are recommended to investigate and intervene in the considerable inpatient burden caused by foot-related conditions.

\section{Strengths and limitations of this study}

- This is the first study to investigate the prevalence of people admitted to hospital because of any foot-related condition within a representative inpatient population.

- This study investigated inpatients from five different hospitals considered to be representative of inpatient populations in Australia.

- Data collectors had specific training and high accuracy in collecting standard self-reported medical history and clinically diagnosed foot-related condition variables.

- As a point-prevalence study, findings are reliant on the days surveyed being representative of standard activity and are unable to determine causal relationships.

\section{INTRODUCTION}

Foot-related conditions can cause high burdens of disease due to high rates of hospitalisation and amputation. ${ }^{1-6}$ In the context of hospitalisation, foot-related conditions typically refer to foot disease or foot trauma. ${ }^{1-10}$ Foot disease typically refers collectively to ulcers, infections, ischaemia and Charcot foot and is usually precipitated by the foot risk factors of peripheral arterial disease (PAD), neuropathy and deformity. ${ }^{1-4}{ }^{10-12}$ Foot trauma typically refers to limb-threatening injuries to the foot caused by high energy trauma. $^{8} 9$

Foot-related conditions have been reported to be present in considerable proportions of specific inpatient populations. ${ }^{1-7}$ Yet, recent reviews conclude the direct foot-related inpatient burden has yet to be studied; that is, the total prevalence of all hospitalisations caused by any foot-related condition within a representative inpatient population. ${ }^{1}{ }^{2}$ One large retrospective study of a national hospital discharge data set reported that $1.2 \%$ of all hospitalisations were caused by 
foot disease; however, it did not report foot trauma. ${ }^{5}$ Therefore, there is a distinct gap in information to quantify the direct inpatient burden caused by foot-related conditions. ${ }^{12}$ Without this information, it is difficult for clinicians, researchers and policymakers to comprehend, compare and address a burden of disease. ${ }^{13}$

Thus, the primary aim of this point-prevalence study was to investigate a representative inpatient population to determine the prevalence of people admitted to hospital for the primary or secondary reason of a foot-related condition. A secondary aim was to investigate the independent factors associated with being admitted to hospital for the reason of a foot-related condition.

\section{METHODS}

Study design

This study was the first in the Foot Disease in Inpatients Study (FDIS) research project. The main objective of FDIS was to investigate the prevalence, and associated factors, of different foot disease disorders and foot risk factors in a representative inpatient population. This was a multisite observational point-prevalence cross-sectional study set in five public hospitals in Queensland, Australia. The authors have adhered to the STROBE reporting checklist for cross-sectional studies (see online supplementary table S1). Site-specific authority was also obtained from each hospital, and written informed consent was voluntarily obtained from all participants.

\section{Settings}

Five public hospitals made up the sites for this study: (1) a major metropolitan hospital ( $>500$ beds) with a catchment population of 900000 in south Queensland; (2) major metropolitan specialty ( $>500$ beds) with a catchment population of 900000 in south Queensland; (3) major regional (200-500 beds) with a catchment population of 220000 in central Queensland; (4) large metropolitan (200-500 beds) with a catchment population of 250000 in south Queensland and (5) large regional hospital (50-99 beds) with a catchment population of 30000 in north Queensland. These hospitals were purposively selected by the authors to maximise the population-based generalisability of any findings by representing each of the different defined categories of peer group hospitals in Australia according to the National Health Performance Authority: ${ }^{14}$ major metropolitan, major regional, large metropolitan, large regional and medium hospitals. ${ }^{14}$ Specialist hospitals are unable to be defined into these peer groups; ${ }^{14}$ thus, the authors decided to include a major metropolitan specialist hospital instead of a medium hospital to further maximise generalisability.

As a point-prevalence study, each hospital had data collected on one day. Practical resource implications meant the same day could not be chosen for all hospitals. After consultation with senior hospital management, a mid-week day (Tuesday to Thursday) was considered to be most representative of standard hospital activity. The designated day for each hospital was decided by the authors according to resource, travel and data collector availability. Data collection days for hospitals in similar regions were separated by 2 months to minimise the possibility of the same participant admission being captured twice. Data collection days were in 2013: major metropolitan (September), major metropolitan specialty (July), major regional (June), large metropolitan (December) and large regional hospital (June).

\section{Participants}

Eligible participants were all adult inpatients ( $>18$ years) present between 8:00 and 17:00 in the hospital on the designated data collection day. An inpatient was defined as a person admitted for at least one night of hospital care for any reason, either the night prior or the night of the designated data collection day as confirmed by the treating medical officer. Exclusion criteria included those $<18$ years of age; those with a cognitive deficit as determined by the Nurse Unit Manager; or those in a paediatric, maternity or psychiatric ward. These criteria are typical of point-prevalence inpatient studies. ${ }^{15-18}$

\section{Sample size calculation}

An inpatient prevalence of $4.6 \%$ was chosen as the basis for the sample size calculation. ${ }^{1}$ This was chosen as a recent systematic review reported that foot wounds had been the most investigated of all inpatient foot-related conditions and $4.6 \%$ was the reported pooled prevalence estimate for inpatient foot wounds from this review. ${ }^{1}$ Therefore, a sample size of 750 participants was calculated for this study based on an inpatient prevalence of $4.6 \%$, a $95 \%$ CI of $3.1 \%$ to $6.1 \%$, and an $\alpha$ level of 0.05 .

\section{Data collection instrument}

A Queensland Foot Disease Form (QFDF) data collection instrument was used to collect all variables (figure 1). The QFDF was modified from a similar validated data collection instrument, the Queensland High Risk Foot Form (QHRFF). ${ }^{19}$ In brief, the QHRFF collects 46 items via self-reported history and clinical diagnoses of foot-related conditions. ${ }^{19}{ }^{20}$ Modifications to the QHRFF to develop the QFDF included enacting any changes recommended by its original authors; ${ }^{19}$ removing variables not applicable to this study and adding variables identified from recent systematic reviews to be applicable to foot-related conditions in inpatients ${ }^{1} 221$ such as reason for admission. ${ }^{15} 22$ The 57-item QFDF contained $36(78 \%)$ of the 46 items that were extensively tested for reliability and validity in the QHRFF. ${ }^{19}$ The authors decided to further test the QFDF by testing the accuracy of data collectors using the QFDF against simulated cases, and testing the concurrent validity of a subsample of study data collected using the QFDF compared with medical records audited for the same data. Both testing procedures are described below. 
Figure 1 QFDF data collection instrument. CKD, chronic kidney disease; CVA, cardiovascular accident; ESKD, end-stage kidney disease; GP, general practitioner; $\mathrm{HbA1c}$, glycated haemoglobin; MI, myocardial infarct; PAD, peripheral arterial disease; QFDF, Queensland Foot Disease Form; UTWCS, University of Texas Wound Classification System.

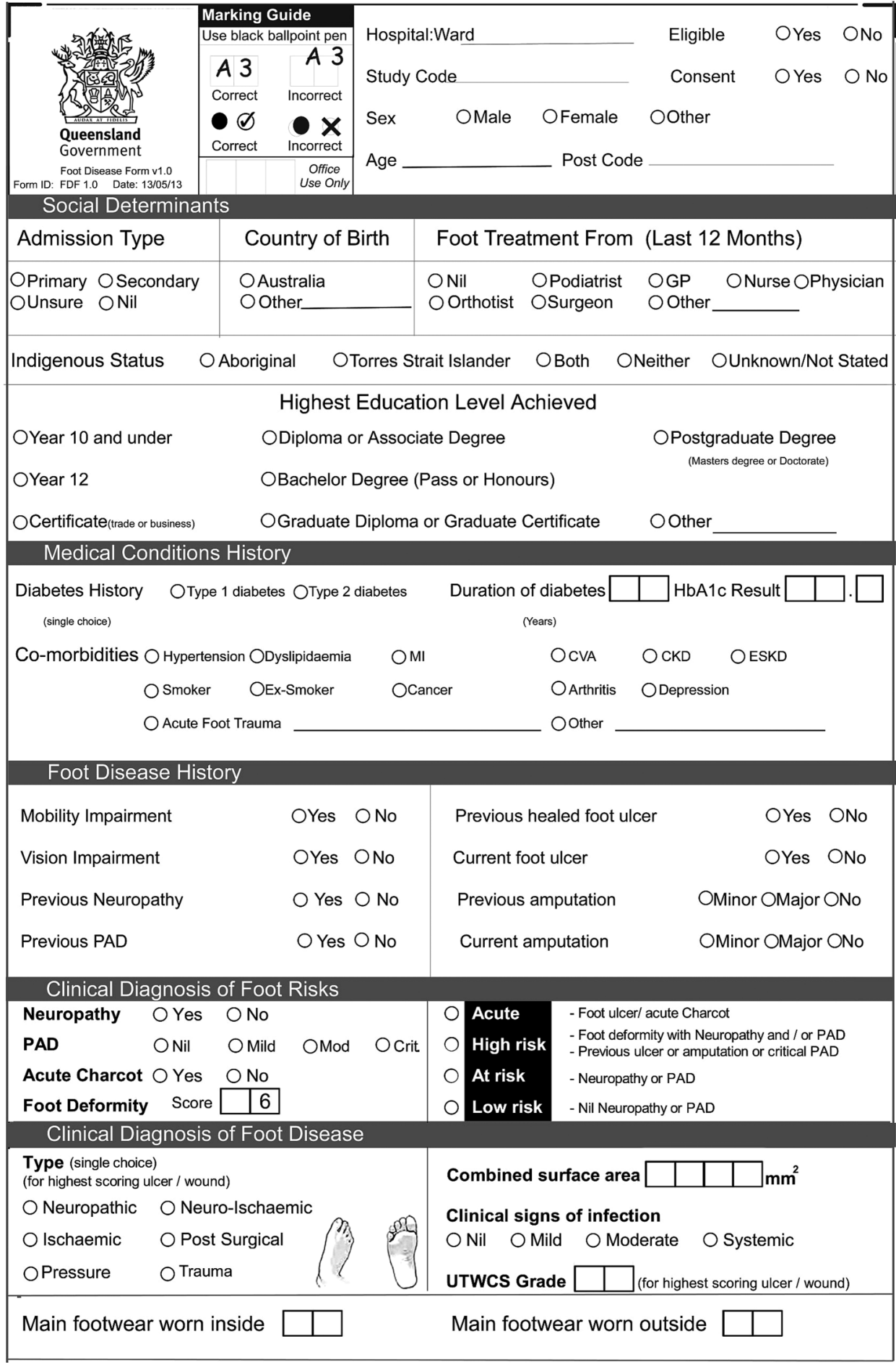

*Modified from Queensland High Risk Foot Form

\section{Variables collected}

Table 1 outlines the criteria, definitions and supporting citations ${ }^{5}$ 8-11 19-39 used for each individual variable collected by the QFDF in this study. Patient explanatory variables were self-reported and grouped into ward, demographic, social determinant, medical condition history, self-care ability, past foot treatment and foot disease history variables. Foot explanatory variables were clinically diagnosed and grouped into foot risk factors, foot disease and foot risk status. The outcome variable of interest for this study was the selfreported identification of a foot-related condition as the participant's primary or secondary reason for admission. From those participants reporting a foot-related condition as a reason for admission, the foot explanatory variable considered to most likely have caused the admission was identified and termed the predominant foot-related condition causing admission. Trained data collectors administered all variables. 
Table 1 Definitions for each item of the QFDF

QFDF item
Ward
Surgical ward
Medical ward
Demographics
Age
Sex
Social determinants
Socioeconomic status
Geographical remoteness
Highest education level
achieved
Born overseas
Indigenous status
Medical condition history
Diabetes
Diabetes type
Hypertension
Dyslipidaemia
MI
CVA
CKD

ESKD

Cancer

Arthritis

\section{Depression}

Acute foot trauma

\section{Smoker}

Ex-smoker

Self-care ability

Mobility impairment

Vision impairment

Footwear worn: inside

Footwear worn: outside

Low-risk footwear

Moderate-risk footwear

High-risk footwear

No footwear worn

\section{Definition}

Participant is in a ward for the purpose of a surgical procedure ${ }^{23}$

Participant is in a ward not for the purpose of a surgical procedure ${ }^{23}$

Participant's age in whole years at time of data collection ${ }^{19} 212324$

Participant is male, female or other ${ }^{19} 212324$

Participant's postcode of usual residence was used to determine Australian Index of Relative Social Disadvantage status ${ }^{21} 25$

Participant's postcode of usual residence was used to determine Accessibility/Remoteness Index of Australia status ${ }^{21} 26$

What is the highest education qualification level you have achieved? ${ }^{21} 2427$

In which country were you born? $?^{24} 27$

Are you of Aboriginal or Torres Strait Islander origin? ${ }^{19} 2324$

Have you ever been told by a doctor or nurse that you have had diabetes? (Should have lasted or likely to last for $6+$ months) ${ }^{1921242728}$

If yes to diabetes, which type of diabetes do you have: type 1 or type $2 ?^{19} 212428$

Have you ever been told by a doctor or nurse that you have had hypertension or high blood pressure? (Should have lasted or likely to last for $6+$ months) ${ }^{19} 2427$

Have you ever been told by a doctor or nurse that you have had dyslipidaemia or high cholesterol? (Should have lasted or likely to last for $6+$ months) ${ }^{19} 24$

Have you ever been told by a doctor or nurse that you have had MI or heart attack? (Should have lasted or likely to last for $6+$ months) $)^{19} 2124$

Have you ever been told by a doctor or nurse that you have had cardiovascular attack or stroke? (Should have lasted or likely to last for 6+ months) ${ }^{19} 212427$

Have you ever been told by a doctor or nurse that you have had CKD? (Should have lasted or likely to last for $6+$ months) $)^{19} 21$

Have you ever been told by a doctor or nurse that you have had kidney failure or do you need dialysis? (Should have lasted or likely to last for $6+$ months) ${ }^{19}$

Have you ever been told by a doctor or nurse that you have had cancer? (Should have lasted or likely to last for $6+$ months) ${ }^{21} 27$

Have you ever been told by a doctor or nurse that you have had arthritis? (Should have lasted or likely to last for $6+$ months $)^{27}$

Have you ever been told by a doctor or nurse that you have had depression? (Should have lasted or likely to last for $6+$ months) ${ }^{24} 27$

Have you had major trauma to your feet that resulted in a fracture, burn, wound or infection that required hospital treatment? ${ }^{89}$

Are you a current smoker? ${ }^{19} 212427$

If no to smoker, did you ever smoke? ${ }^{19} 212427$

Are you able to walk without the help of an aide? ${ }^{11} 21$

Are you able to read a newspaper (with glasses if needed) ${ }^{11} 21$

From a sheet displaying 16 different types of footwear: What is the type of shoes you have worn most inside the house over the past 12 months? ${ }^{21} 2930$

From a sheet displaying 16 different types of footwear: What is the type of shoes you have worn most outside the house over the past 12 months? 212930

Participant identified picture of walking shoe, runner, oxford shoe, boot or bespoke footwear as footwear worn most ${ }^{29} 30$

Participant identified picture of moccasin, ugg boot, slipper or backless slipper as footwear worn most $^{29} 30$

Participant identified picture of high heels, flip flop, court shoe, mule or sandal as footwear worn most $^{29} 30$

Participant identified picture of socks only or barefoot as footwear worn most ${ }^{29} 30$ 
Table 1 Continued

QFDF item Definition

Past foot treatment
Yes

Podiatry

GP

Physician

Surgeon

Nurse

Orthotist

Other

Foot disease history

Previous PN

Previous PAD

Previous foot ulcer

Previous amputation

Foot risk factors

PN

\section{PAD}

\section{Mild PAD}

Moderate PAD

Critical PAD (ischaemia)

Foot deformity

\section{Foot disease \\ Acute Charcot}

Current foot ulcer

Current foot infection

Foot risk status

Low risk

At risk

High risk

Acute
Have you been treated for a foot problem in the past 12 months? (Excluding in the current admission) $)^{1931}$

Have you been treated for a foot problem by a podiatrist in the past 12 months? (Excluding in the current admission) $)^{19} 31$

Have you been treated for a foot problem by a GP in the past 12 months? (Excluding in the current admission) $)^{1931}$

Have you been treated for a foot problem by another medical physician in the past 12 months? (Excluding in the current admission) ${ }^{19} 31$

Have you been treated for a foot problem by a surgeon in the past 12 months? (Excluding in the current admission) $)^{19} 31$

Have you been treated for a foot problem by a nurse in the past 12 months? (Excluding in the current admission) $)^{19} 31$

Have you been treated for a foot problem by an orthotist in the past 12 months? (Excluding in the current admission) $)^{19} 31$

Have you been treated for a foot problem by any other health professional/s in the past 12 months? (Excluding in the current admission) ${ }^{19} 31$

Have you ever been told by a doctor or nurse that you have had PN? (Should have lasted or likely to last for $6+$ months) ${ }^{19}$

Have you ever been told by a doctor or nurse that you have had PAD? (Should have lasted or likely to last for $6+$ months) ${ }^{1921}$

Have you ever had a foot ulcer that has healed ${ }^{19} 21$

Have you ever had an amputation? Plus, a clinical examination to verify previous healed lower extremity amputation site ${ }^{1921}$

A lack of protective sensation to a $10 \mathrm{~g}$ monofilament on at least 2 of 3 plantar forefoot locations on at least one foot ${ }^{11} 19283233$

Absence of at least one palpable foot pulse and a toe systolic pressure $<70 \mathrm{~mm} \mathrm{Hg}$ on at least one foot ${ }^{1019} 33-35$

Toe systolic pressure $=51-70 \mathrm{~mm} \mathrm{Hg}^{10} 19$ 33-35

Toe systolic pressure $=31-50 \mathrm{~mm} \mathrm{Hg}^{10} 193536$

Toe systolic pressure $=<30 \mathrm{~mm} \mathrm{Hg}^{10} 193335$

A score of at least 3 using the 6-point foot deformity score on at least one foot (1 point each allocated for small muscle wastage, bony prominence, prominent metatarsal heads, hammer/ claw toes, limited joint mobility and Charcot deformity) ${ }^{192932}$

A red, hot, swollen, unilateral neuropathic foot without a local foot wound on at least one foot $^{19} 2832$

Do you have a current foot ulcer or sore? Plus, a clinical examination to verify a full thickness wound beneath the ankle ${ }^{19} 37$

At least 2 manifestations of inflammation beneath the ankle (purulence, erythema, pain, tenderness, warmth or induration) $)^{19} 333839$

Nil foot disease history or clinical diagnosis of current foot disease, PN or PAD identified during the clinical examination ${ }^{19} 32$

Clinical diagnosis of PN and/or PAD (excluding critical PAD) identified during the clinical examination ${ }^{19} 32$

Clinical diagnosis of critical PAD, or, foot deformity with PN and/or PAD, or, self-reported previous foot ulcer or amputation ${ }^{19} 32$

Current foot wound or acute Charcot $^{19} 32$

Foot-related condition admission

Primary reason for

admission

Secondary reason for

Is a foot condition the main reason for your hospital admission? $?^{5} 202223$

Is a foot condition another reason for your hospital admission? $?^{522} 23$ admission

CKD, chronic kidney disease; CVA, cardiovascular accident; ESKD, end-stage kidney disease; GP, general practitioner; MI, myocardial infarct; PAD, peripheral arterial disease; PN, peripheral neuropathy; QFDF, Queensland Foot Disease Form. 


\section{Data collection procedure}

\section{Data collector training}

Data collectors were 27 publicly employed podiatrists who routinely used the QHRFF in their existing clinical practice. Data collectors were assisted by 25 final year undergraduate podiatry students and 4 publicly employed other staff. The role of the assistants was to help the data collectors with administering the consenting and self-reported history processes only. All data collectors and assistants participated in a 3-hour training session $<1$ month prior to their designated data collection day.

\section{Data collector testing}

All data collectors were tested on their use of the 57-item QFDF, using simulated cases to assess their data collection accuracy immediately pretraining and posttraining session. A minimum of $80 \%$ accuracy on the 57 -item simulated cases was required to be endorsed as a data collector and differences in pretraining and posttraining scores were analysed.

\section{Data collection}

Data collection occurred between 8:00 and 17:00 on the designated day. Data collection teams of up to eight people were allocated up to five wards of potentially eligible participants for data collection. After completing the voluntary consenting procedure, included participants were questioned to determine their self-report history variables. Participants were then shown a footwear form (modified with permission from Barton et $a \hat{l}^{30}$ ) containing 16 footwear styles to identify their main footwear worn inside and outside the house in the previous 12 months. All participants then underwent a non-invasive physical examination by a data collector to determine their clinically diagnosed variables. All participant data were recorded on the QFDF and all completed QFDF data collection forms were checked at the conclusion of each hospital data collection day by the authors for errors or omissions. Any missing data or potential data errors were clarified with the data collector concerned.

\section{Data collector audit}

As aforementioned, a subsample of data collected from participants (study data) was tested for concurrent validity with the participants' medical records (medical records). As the study was conducted in different regions, a random sample was unable to be tested due to resource constraints. Therefore, to be representative of the different wards and hospitals in the study, a subsample $(\sim 5 \%$ of the required study sample size $)$ was taken from one general medical and one general surgical ward located in the large metropolitan hospital, which was the third largest (middle-sized) hospital. The process for the audit involved first collecting the study data from the subsample of participants as per the data collection procedure. The hospital medical records of those participants included in the subsample were then audited on the same day by two authors who were blinded to the subsample study data collected. The authors were instructed to review the medical record and complete all applicable variables if noted anywhere in the medical record using a QFDF. The applicable variables recorded from the medical records were then compared with the study data collected for agreement.

\section{Statistical analysis}

All data were analysed using SPSS V.22.0 for Windows (SPSS, Chicago, Illinois, USA) or GraphPad Software. Descriptive statistics were used to display all variables, using means and SDs for continuous variables or proportions for categorical variables. Prevalence with $95 \%$ CIs were calculated using a modified Wald method for outcome variables. ${ }^{40} \chi^{2}$ or Kruskal-Wallis tests were used to test differences between hospitals for categorical variables and t-tests or analysis of variance to test differences between hospitals for continuous variables. ${ }^{41}$ Univariate logistic regression analyses were undertaken to test for crude associations with the outcomes. ${ }^{41-43}$

Multivariate logistic regression was used to analyse for independent associations. ${ }^{42}{ }^{43}$ As this study was investigating a new field, a data-driven backwards stepwise method was chosen. ${ }^{42}{ }^{43}$ All variables achieving crude associations $(p<0.2)$, except those deemed illogical, were entered into the backwards stepwise model, nonsignificant variables $(p>0.05)$ were removed at each step, until only variables achieving statistical significance remained $(p<0.05)$ and their ORs reported (unadjusted model). ${ }^{42}$ This model method was consistent with similar foot-related studies. ${ }^{31} 36$ 44-46 Collinearity was tested for all models using correlation matrix $(>0.9)$, tolerance $(<0.1)$ and variance inflation factor $(>10) .{ }^{42} 43$ If collinearity was identified, the variable with the lowest OR in the univariate analysis was removed. The Hosmer and Lemeshow goodness of fit, Omnibus and Negelkerke pseudo $\mathrm{R}^{2}$ tests were used at each step of all models to indicate goodness of fit, significance, parsimony and potential variance of the outcome variable explained by the model, respectively. ${ }^{42}{ }^{43}$ The final unadjusted model was then tested for confounding by re-entering in each non-included explanatory variable to see if it confounded the independent explanatory variables in the unadjusted model. ${ }^{42}{ }^{43} \mathrm{~A}$ confounder was defined, and remained in the model, as changing the $\beta$ effect estimates of at least one unadjusted independent explanatory variables by $>20 \%$ (adjusted model) ${ }^{42}$ Two different multivariate models were assessed for each outcome variable. The first used all available explanatory variables, except the summarised foot risk status variable (model 1). The second used the summarised foot risk status variable, instead of foot disease history, foot risk factors and foot disease explanatory variables (model 2). Missing data were treated by excluding cases with missing data as missing data were minimal $(<5 \%$ in all models). ${ }^{42}$ 
Lastly, $\kappa$ for dichotomous variables, weighted $\kappa(w \mathrm{~K})$ for ordinal variables and intraclass correlation (ICC; models 2 and 1) for continuous variables were used to test for measures of agreement for the data collector testing and audit. ${ }^{41} 4748 \mathrm{~K}$ and wK (SEs ) strengths were categorised as: no agreement $<0$; slight agreement $=0-0.20$; fair agreement $=0.21-0.40$; moderate agreement $=0.41-0.6$; substantial agreement $=0.61-0.8$ and near-perfect agreement=0.81-1.0. ${ }^{41} 47 \quad 48$ ICG (SD) strengths were categorised as: weak-moderate agreement $<0.75$ and strong agreement $>0.75 .^{41}$

\section{RESULTS}

\section{Characteristics}

Online supplementary table S2 reports the demographic characteristics of the 1146 total inpatients present during the study. Of these, 263 (23\%) patients were non-eligible and excluded: 248 due to cognitive impairment and 15 for other reasons (including children, non-English speaking or unavailable). Non-eligible patients were older $(\mathrm{p}<0.001)$ with no differences in sex $(\mathrm{p}=0.717)$. Of the 883 eligible patients, 733 (83\%) consented. There were no differences in age $(p=0.187)$ or sex $(\mathrm{p}=0.198)$ between those consenting and non-consenting.

Table 2 reports the characteristics of the 733 included participants. Overall, mean age (SD) was 62.0 (18.6) years and $55.8 \%$ were males. Differences were evident between hospitals for demographic, social determinant, medical history, self-care ability, past foot treatment, foot disease history and foot risk status variables $(p<0.05)$. No differences between hospitals were recorded for foot risk factor and foot disease variables $(\mathrm{p}<0.05)$.

\section{Prevalence}

Primary reason for admission for foot-related conditions were identified in 54 participants $(7.4 \%$ (95\% CI $5.7 \%$ to $9.5 \%)$ ) and 15 of those had diabetes $(2.0 \%$ (1.2\% to $3.4 \%)$; table 2). The predominant causes of these were foot disease in 36 participants (4.9\% (3.6\% to 6.7\%); 17 foot infection, 13 critical PAD, 6 foot ulcer), foot trauma in 15 participants $(2.1 \%(1.2 \%$ to $3.4 \%))$ and 3 others were unable to be determined with the variables collected. Higher proportions of primary foot-related admissions existed in the major regional $(12.2 \%)$ and major metropolitan general hospitals $(10.7 \%)$ as compared with the other hospitals $(\mathrm{p}<0.05)$.

Secondary reason for admission for foot-related conditions were identified in 28 participants $(3.8 \%$ (2.6\% to $5.5 \%)$ ) and 19 of those had diabetes $(2.6 \%(1.6 \%$ to $4.0 \%)$; table 2). The predominant causes of these were foot disease in 13 participants (1.8\% (1.0\% to 3.0\%); 9 foot ulcers, 3 foot infections, 1 critical PAD), foot trauma in $1(0.1 \%(0 \%$ to $0.8 \%))$ and 14 others were unable to be determined. No differences in proportions of secondary foot-related admissions between hospitals were identified.

\section{Independent associated factors}

Table 3 reports unadjusted and adjusted OR (95\% CIs) for variables achieving significance for primary reason for admission for foot-related conditions. Univariate analyses $(p<0.2)$ identified 20 variables eligible for model 1 and 12 for model 2 (see online supplementary table S3). Current foot ulcer was excluded as collinearity was identified with current foot infection. Model 1 identified six unadjusted independent associated factors: critical $\mathrm{PAD}$, current foot infection, acute foot trauma, past surgeon treatment, past general practitioner (GP) treatment and myocardial infarct $(\mathrm{MI})$ history (all $\mathrm{p}<0.05$ ). Identified confounders were: socioeconomic status, diabetes, chronic kidney disease (CKD) and dyslipidaemia. After adjusting, all factors remained significant (all $\mathrm{p}<0.01)$, except MI $(\mathrm{p}>0.2)$. Model 2 identified four unadjusted independent associated factors: acute foot risk status, high foot risk status, past surgeon treatment and past GP treatment (all $\mathrm{p}<0.05)$. Identified confounders were: diabetes, MI, CKD, acute foot trauma and past podiatry treatment. After adjusting, all factors remained significant (all $\mathrm{p}<0.001)$.

Table 4 reports unadjusted and adjusted OR $(95 \%$ CIs) for variables achieving significance for secondary reason for admission for foot-related conditions. Univariate analyses $(\mathrm{p}<0.2)$ identified 16 variables eligible for model 1 and 10 for model 2 (see online supplementary table S3). Current foot infection was excluded as collinearity was identified with current foot ulcer. Model 1 identified two unadjusted independent associated factors: diabetes and current foot ulcer (both $\mathrm{p}<0.001)$. Identified confounders were: mobility impairment and previous foot ulcer. After adjusting, both factors remained significant (both $\mathrm{p}<0.01$ ). Model 2 identified two unadjusted independent associated factors: diabetes and acute foot risk status (both $\mathrm{p}<0.001$ ). No adjustment was performed as no confounders were identified.

\section{Data collector testing and audit results}

Online supplementary table S4 reports an improvement in the data collectors post-training scores compared with pretraining scores $(\mathrm{p}<0.001)$. All participants scored $>90 \%$ in the post-test. Online supplementary table S5 reports the strengths of agreement between the study data and medical records data for the 44 eligible and 28 consenting participants in the subsample. Of the 19 applicable variables tested, $12(63 \%)$ had near-perfect/ strong, $2(11 \%)$ substantial, $3(16 \%)$ moderate and 2 $(11 \%)$ had fair agreement. In variables reporting less than near-perfect/strong agreement, study data identified more cases than medical records.

\section{DISCUSSION}

\section{Principal findings}

We believe this is the first study to investigate the direct inpatient burden caused by all foot-related conditions within a representative inpatient population. Our 
Table 2 Participant characteristics for each hospital site (number (\%) unless otherwise stated)

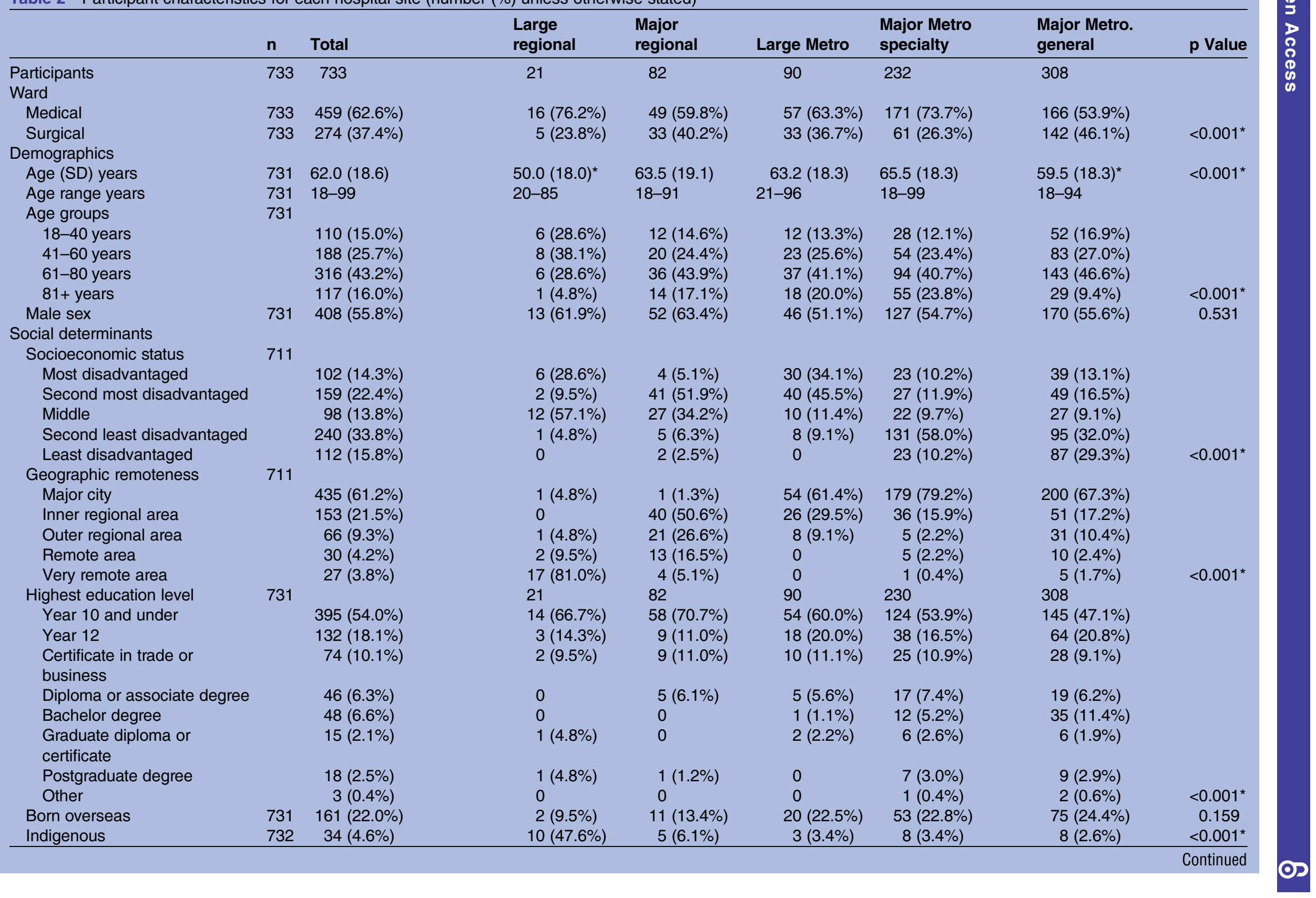


Table 2 Continued

\begin{tabular}{|c|c|c|c|c|c|c|c|c|}
\hline & $\mathbf{n}$ & Total & $\begin{array}{l}\text { Large } \\
\text { regional }\end{array}$ & $\begin{array}{l}\text { Major } \\
\text { regional }\end{array}$ & Large Metro & $\begin{array}{l}\text { Major Metro } \\
\text { specialty }\end{array}$ & $\begin{array}{l}\text { Major Metro. } \\
\text { general }\end{array}$ & p Value \\
\hline \multicolumn{9}{|l|}{ Medical condition history } \\
\hline Diabetes & 733 & $172(23.5 \%)$ & $6(28.6 \%)$ & $20(24.4 \%)$ & $18(20.0 \%)$ & $66(28.4 \%)$ & $62(20.1 \%)$ & 0.195 \\
\hline Type 2 diabetes $†$ & & $162(22.1 \%)$ & $6(28.6 \%)$ & $20(24.4 \%)$ & $18(20.0 \%)$ & $59(25.4 \%)$ & $59(19.2 \%)$ & 0.139 \\
\hline Hypertension & 733 & $359(49.0 \%)$ & $11(52.4 \%)$ & $40(48.8 \%)$ & $52(57.8 \%)$ & $129(55.6 \%)$ & $127(41.2 \%)$ & $0.006^{*}$ \\
\hline Dyslipidaemia & 733 & $234(31.9 \%)$ & $6(28.6 \%)$ & $30(36.6 \%)$ & $34(37.8 \%)$ & $91(39.2 \%)$ & $73(23.7 \%)$ & $0.001^{*}$ \\
\hline Myocardial infarct & 733 & $146(19.9 \%)$ & $4(19.0 \%)$ & 10 (12.2\%) & $18(20.0 \%)$ & $67(28.9 \%)$ & 47 (15.3\%) & $0.001^{*}$ \\
\hline Cerebrovascular accident & 733 & $85(11.6 \%)$ & $1(4.8 \%)$ & $10(12.2 \%)$ & $10(11.1 \%)$ & $36(15.5 \%)$ & $28(9.1 \%)$ & 0.173 \\
\hline Chronic kidney disease & 733 & $89(12.1 \%)$ & $1(4.8 \%)$ & $9(11.0 \%)$ & $15(16.7 \%)$ & $31(13.4 \%)$ & $33(10.7 \%)$ & 0.431 \\
\hline End-stage kidney disease $†$ & 733 & $9(1.2 \%)$ & 0 & $3(3.7 \%)$ & $1(1.1 \%)$ & 0 & $5(1.6 \%)$ & NA \\
\hline Cancer & 733 & $174(23.7 \%)$ & $1(4.8 \%)$ & $19(23.2 \%)$ & $26(28.9 \%)$ & $43(18.5 \%)$ & 85 (27.6\%) & $0.021^{*}$ \\
\hline Arthritis & 733 & $274(37.4 \%)$ & $5(23.8 \%)$ & $36(44.4 \%)$ & $40(44.4 \%)$ & $91(39.2 \%)$ & $102(33.1 \%)$ & 0.100 \\
\hline Depression & 733 & $191(26.1 \%)$ & $2(9.5 \%)$ & 29 (35.4\%) & $28(31.1 \%)$ & $55(23.7 \%)$ & 77 (25.0\%) & 0.069 \\
\hline Acute foot trauma & 733 & $26(3.5 \%)$ & $1(4.8 \%)$ & $4(4.9 \%)$ & $6(6.7 \%)$ & $2(0.9 \%)$ & $13(4.2 \%)$ & 0.079 \\
\hline Smoker & 733 & $104(14.2 \%)$ & 7 (33.3\%) & $18(22.0 \%)$ & 17 (18.9\%) & $12(5.2 \%)$ & $50(16.2 \%)$ & $<0.001^{*}$ \\
\hline Ex-smoker & 733 & 304 (41.5\%) & $10(47.6 \%)$ & $34(41.5 \%)$ & $35(38.9 \%)$ & $109(47.0 \%)$ & $116(37.7 \%)$ & 0.256 \\
\hline \multicolumn{9}{|l|}{ Self-care ability } \\
\hline Mobility impairment & 729 & 242 (33.2\%) & $4(19.0 \%)$ & $36(43.9 \%)$ & $37(41.1 \%)$ & 78 (33.8\%) & 87 (28.5\%) & $0.020^{*}$ \\
\hline Vision impairment & 730 & 110 (15.1\%) & $2(9.5 \%)$ & 10 (12.2\%) & $12(13.5 \%)$ & $41(17.7 \%)$ & 45 (14.7\%) & 0.637 \\
\hline Footwear worn: inside & 728 & & & & & & & \\
\hline Low-risk footwear & & $81(11.1 \%)$ & 0 & $9(11.0 \%)$ & $5(5.6 \%)$ & $29(12.7 \%)$ & 38 (12.4\%) & \\
\hline Moderate-risk footwear & & $263(36.1 \%)$ & 2 (9.5\%) & 35 (42.7\%) & $28(31.1 \%)$ & $108(47.2 \%)$ & $90(29.4 \%)$ & \\
\hline High-risk footwear & & $139(19.1 \%)$ & $11(52.4 \%)$ & $12(14.6 \%)$ & $17(18.9 \%)$ & $33(14.4 \%)$ & $66(21.6 \%)$ & \\
\hline No footwear worn & & 245 (33.7\%) & $8(38.1 \%)$ & $26(31.7 \%)$ & 40 (44.4\%) & $59(25.8 \%)$ & 112 (36.6\%) & $<0.001^{*}$ \\
\hline Footwear worn: outside & 726 & & & & & & & \\
\hline Low-risk footwear & & $386(53.2 \%)$ & $12(57.1 \%)$ & $46(56.1 \%)$ & $50(55.6 \%)$ & $118(51.5 \%)$ & $160(52.6 \%)$ & \\
\hline Moderate-risk footwear & & 75 (10.3\%) & $1(4.8 \%)$ & $8(9.8 \%)$ & $10(11.1 \%)$ & 34 (14.8\%) & $22(7.2 \%)$ & \\
\hline High-risk footwear & & $250(34.4 \%)$ & $8(38.1 \%)$ & $26(31.7 \%)$ & $29(32.2 \%)$ & 74 (32.3\%) & $113(37.2 \%)$ & \\
\hline No footwear worn & & $15(2.1 \%)$ & 0 & $2(2.4 \%)$ & $1(1.1 \%)$ & $3(1.3 \%)$ & $9(3.0 \%)$ & 0.405 \\
\hline Past foot treatment & 733 & & & & & & & \\
\hline Yes & & $256(34.9 \%)$ & $6(28.6 \%)$ & $38(46.3)$ & $31(34.4 \%)$ & $83(35.8 \%)$ & $98(31.8 \%)$ & 0.167 \\
\hline Podiatrist & & $180(24.6 \%)$ & $4(19.0 \%)$ & $21(25.6 \%)$ & $23(25.6 \%)$ & $70(30.2 \%)$ & $62(20.1 \%)$ & 0.105 \\
\hline GP & & $93(12.7 \%)$ & $3(14.3 \%)$ & $22(26.8 \%)$ & $8(8.9 \%)$ & $19(8.2 \%)$ & $41(13.3 \%)$ & $<0.001^{*}$ \\
\hline Surgeon & & $36(4.9 \%)$ & 0 & $6(7.3 \%)$ & $2(2.2 \%)$ & $6(2.6 \%)$ & $22(7.1 \%)$ & 0.050 \\
\hline Physician & & $21(2.9 \%)$ & 2 (9.5\%) & $7(8.5 \%)$ & 0 & $4(1.7 \%)$ & $8(2.6 \%)$ & $0.002^{*}$ \\
\hline Nurse & & $20(2.7 \%)$ & $1(4.8 \%)$ & $3(3.7 \%)$ & 0 & $6(2.6 \%)$ & $10(3.2 \%)$ & 0.486 \\
\hline Orthotist & & $4(0.5 \%)$ & 0 & $1(1.2 \%)$ & $1(1.1 \%)$ & 0 & $2(0.6 \%)$ & NA \\
\hline Other & & $9(1.2 \%)$ & $3(14)$ & 0 & $1(1.1 \%)$ & 0 & $5(1.6 \%)$ & NA \\
\hline \multicolumn{9}{|l|}{ Foot disease history } \\
\hline $\begin{array}{l}\text { Previous peripheral } \\
\text { neuropathy }\end{array}$ & 728 & 99 (13.6\%) & 0 & $9(11.0 \%)$ & $13(14.4 \%)$ & $20(8.7 \%)$ & 57 (18.8\%) & $0.004^{*}$ \\
\hline Previous PAD & 728 & $97(13.3 \%)$ & $1(4.8 \%)$ & $7(8.5 \%)$ & $13(14.4 \%)$ & $17(7.4 \%)$ & 59 (19.4\%) & $0.001^{*}$ \\
\hline
\end{tabular}


Table 2 Continued

\begin{tabular}{|c|c|c|c|c|c|c|c|c|}
\hline & $\mathbf{n}$ & Total & $\begin{array}{l}\text { Large } \\
\text { regional }\end{array}$ & $\begin{array}{l}\text { Major } \\
\text { regional }\end{array}$ & Large Metro & $\begin{array}{l}\text { Major Metro } \\
\text { specialty }\end{array}$ & $\begin{array}{l}\text { Major Metro. } \\
\text { general }\end{array}$ & p Value \\
\hline Previous foot ulcer & 731 & $72(9.8 \%)$ & $1(4.8 \%)$ & $6(7.3 \%)$ & $9(10.0 \%)$ & $17(7.4 \%)$ & $39(12.7 \%)$ & 0.228 \\
\hline Previous amputation & 731 & $30(4.1 \%)$ & 0 & $2(2.4 \%)$ & $3(3.3 \%)$ & $6(2.6 \%)$ & $19(6.2 \%)$ & 0.181 \\
\hline \multicolumn{9}{|l|}{ Foot risk factors } \\
\hline Peripheral neuropathy & 728 & $160(22.0 \%)$ & $3(14.3 \%)$ & $24(29.6 \%)$ & $16(17.8 \%)$ & $58(25.1 \%)$ & $59(19.3 \%)$ & 0.137 \\
\hline PAD & 728 & & & & & & & \\
\hline Mild PAD & & $69(9.5 \%)$ & $2(9.5 \%)$ & $7(8.5 \%)$ & $8(8.9 \%)$ & 25 (10.8\%) & 27 (8.9\%) & \\
\hline Moderate PAD & & $51(7.0 \%)$ & 0 & $5(6.1 \%)$ & $7(7.8 \%)$ & $18(7.8 \%)$ & $21(6.9 \%)$ & \\
\hline Critical PAD & & $33(4.5 \%)$ & $1(4.8 \%)$ & $2(2.4 \%)$ & $3(3.3 \%)$ & $8(3.5 \%)$ & $19(6.3 \%)$ & 0.887 \\
\hline Foot deformity & 706 & 158 (22.4\%) & $2(9.5 \%)$ & $13(16.0 \%)$ & $20(22.7 \%)$ & $51(22.5 \%)$ & $72(24.9 \%)$ & 0.293 \\
\hline \multicolumn{9}{|l|}{ Foot disease } \\
\hline Acute Charcot & 730 & $2(0.3 \%)$ & 0 & 0 & 0 & $2(0.9 \%)$ & 0 & NA \\
\hline Current foot ulcer & 732 & $46(6.3 \%)$ & 0 & $6(7.3 \%)$ & $5(5.6 \%)$ & $10(4.3 \%)$ & $25(8.1 \%)$ & 0.298 \\
\hline Current foot infection & 723 & $24(3.3 \%)$ & 0 & $5(6.2 \%)$ & $3(3.3 \%)$ & $5(2.2 \%)$ & $11(3.6 \%)$ & 0.405 \\
\hline Foot risk status & 731 & & & & & & & \\
\hline Low risk & & 445 (60.9\%) & $15(71.4 \%)$ & $43(52.4 \%)$ & 59 (65.6\%) & $132(57.1 \%)$ & $196(63.8 \%)$ & \\
\hline At risk & & $111(15.2 \%)$ & $1(4.8 \%)$ & $20(24.4 \%)$ & $9(10.0 \%)$ & $50(21.6 \%)$ & $31(10.1 \%)$ & \\
\hline High risk & & 109 (14.9\%) & $4(19.0 \%)$ & $8(9.8 \%)$ & $16(17.8 \%)$ & $37(16.0 \%)$ & $44(14.4 \%)$ & \\
\hline Acute & & $66(9.0 \%)$ & $1(4.8 \%)$ & $11(13.4 \%)$ & $6(6.7 \%)$ & $12(5.2 \%)$ & $36(11.7 \%)$ & $0.001^{*}$ \\
\hline $\begin{array}{l}\text { Foot-related condition admission } \\
(95 \% \mathrm{Cl})\end{array}$ & 732 & $82(11.2 \%)(9.1$ to 13.7$)$ & $1(4.8 \%)$ & $13(15.9 \%)$ & $6(6.7 \%)$ & $14(6.0 \%)$ & $48(15.6 \%)$ & $0.002^{*}$ \\
\hline Primary reason $(95 \% \mathrm{Cl})$ & 732 & $54(7.4 \%)(5.7$ to 9.5$)$ & $1(4.8 \%)$ & $10(12.2 \%)$ & $5(5.6 \%)$ & $5(2.2 \%)$ & $33(10.7 \%)$ & $0.002^{*}$ \\
\hline Secondary reason $(95 \% \mathrm{Cl})$ & 732 & $28(3.8 \%)(2.6$ to 5.5$)$ & 0 & $3(3.7 \%)$ & $1(1.1 \%)$ & $9(3.9 \%)$ & $15(4.9 \%)$ & NA \\
\hline
\end{tabular}

*p Value of $<0.05$

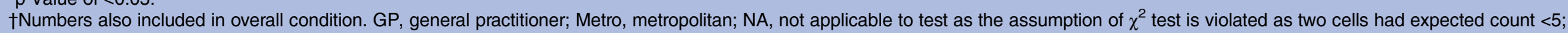
$\mathrm{PAD}$, peripheral arterial disease. 
Table 3 Independent associated factors for primary admissions for foot-related conditions using multivariate logistical regression (ORs $(95 \% \mathrm{Cl})$ )

\begin{tabular}{|c|c|c|c|c|}
\hline Risk factor & Unadjusted & p Value & Adjusted & p Value \\
\hline \multicolumn{5}{|l|}{ Model 1} \\
\hline Myocardial infarct & $0.15(0.03$ to 0.70$)$ & $0.016^{*}$ & $0.34(0.06$ to 1.90$)$ & 0.219 \\
\hline Acute foot trauma & 29.49 (7.28 to 119.48$)$ & $<0.001^{*}$ & $73.32(15.86$ to 338.92$)$ & $<0.001^{*}$ \\
\hline PAD & & $<0.001^{*}$ & & $<0.001^{*}$ \\
\hline Nil PAD & Referent & & Referent & \\
\hline Mild PAD & 0 & NA & 0 & NA \\
\hline Moderate PAD & 2.37 (0.62 to 9.04$)$ & 0.207 & 5.45 (1.05 to 28.23$)$ & 0.044 \\
\hline Critical PAD & $53.60(16.82$ to 170.84$)$ & $<0.001^{*}$ & $140.56(30.82$ to 641.04$)$ & $<0.001^{\star}$ \\
\hline Current foot infection & 29.39 (7.52 to 114.83$)$ & $<0.001^{*}$ & 53.11 (9.89 to 285.17 ) & $<0.001^{*}$ \\
\hline Past GP treatment & 4.65 (1.64 to 13.20$)$ & $0.004^{\star}$ & 7.61 (2.30 to 25.19 ) & $0.001^{*}$ \\
\hline Past surgeon treatment & 5.88 (1.66 to 20.81$)$ & $0.006^{*}$ & 6.98 (1.91 to 25.54$)$ & $0.003^{*}$ \\
\hline \multirow[t]{2}{*}{ Model 1 results: } & Pseudo $R^{2}$ : 0.602; & Missing: 14 (1.9\%); & Pseudo $R^{2}$ : 0.657; & Missing: 36 (4.9\%); \\
\hline & Omnibus: $d f=8, p=<0.001$ & $H \& L: p=0.013$ & $\begin{array}{l}\text { Omnibus: } d f=15, \\
p=<0.001\end{array}$ & $H \& L: p=0.880$ \\
\hline Model 2 & + Past foot treatment & & & \\
\hline Foot risk status & & $<0.001^{*}$ & & $<0.001^{\star}$ \\
\hline Low risk & Referent & & Referent & \\
\hline At risk & $1.66(0.15$ to 18.76$)$ & 0.682 & 2.01 (0.18 to 23.16$)$ & 0.574 \\
\hline High risk & 23.12 (5.05 to 105.95$)$ & $<0.001^{\star}$ & 39.57 (8.15 to 192.05$)$ & $<0.001^{*}$ \\
\hline Acute & $181.44(40.52$ to 812.51$)$ & $<0.001^{*}$ & 158.63 (30.34 to 829.51$)$ & $<0.001^{*}$ \\
\hline Past GP treatment & $2.70(1.17$ to 6.25$)$ & $0.020^{*}$ & $6.40(2.36$ to 17.40$)$ & $<0.001^{\star}$ \\
\hline Past surgeon treatment & 4.31 (1.49 to 12.44$)$ & $0.007^{\star}$ & 11.62 (3.46 to 39.03$)$ & $<0.001^{*}$ \\
\hline \multirow[t]{2}{*}{ Model 2 results: } & Pseudo $R^{2}$ : 0.582; & Missing: 2 (0.3\%); & Pseudo $R^{2}$ : 0.638; & Missing: 2 (0.3\%); \\
\hline & Omnibus: $d f=5, p=<0.001$ & $H \& L: p=0.861$ & $\begin{array}{l}\text { Omnibus: } d f=10 \\
p=<0.001\end{array}$ & $H \& L: p=0.954$ \\
\hline
\end{tabular}

findings indicate $7.4 \%$ of all inpatients were hospitalised for the primary reason of a foot-related condition, including $4.9 \%$ for foot disease and $2.1 \%$ foot trauma. Interestingly, only $28 \%$ of those had diabetes. An additional $3.8 \%$ were hospitalised with a foot-related condition as a secondary reason for admission, including $1.8 \%$ for foot disease and $0.1 \%$ for foot trauma. Being admitted for the primary reason of a foot-related condition was independently associated with having critical PAD, foot infection, foot trauma or past foot treatment by a surgeon or GP. Whereas, being admitted for a secondary reason of a foot-related condition was independently associated with having diabetes or a current foot ulcer. Overall, these findings suggest the direct inpatient burden caused by foot-related conditions is significantly higher than previously reported, affecting 1 in 13 inpatients with the majority not related to diabetes.

\section{Interpretations of findings}

The large disparity between our $7.4 \%$ direct foot-related inpatient burden finding and the $1.2 \%$ in the only previous similar study ${ }^{5}$ may be explained by a number of methodological differences. The previous study retrospectively investigated foot disease codes only from a standard hospital discharge data set to identify patients, ${ }^{5}$ compared with our study which prospectively examined for all possible foot-related conditions. Yet, our study still reported a much higher rate for those hospitalised for foot disease $(4.9 \%)$ compared with the previous study $(1.2 \%) .{ }^{5}$ Retrospective analyses compared with prospective examinations have been found to under-report foot-related admissions in the same Australian inpatient population by threefold. ${ }^{12}$ Additionally, the previous study investigated hospital admissions, ${ }^{5}$ whereas our study investigated a one occupied hospital bed day period. Foot-related admissions use threefold the number of bed days than average hospital admissions in Australia. ${ }^{3}{ }^{6}$ These methodological improvements compared with the previous study suggest our findings are plausible and much higher than previously reported.

We found only $28 \%$ of foot-related hospitalisations were in people with diabetes which was similar to the $15 \%$ reported in the previous study. ${ }^{5}$ This suggests the majority of the inpatient foot-related burden may not be caused by diabetes as has been traditionally considered. ${ }^{34}$ Our findings equate to $2.0 \%$ of all inpatients, on a given day, being in hospital because of diabetes-related foot disease in Queensland. Considering a recent retrospective study of the Queensland hospital discharge data set identified that $0.9 \%$ of all hospital bed days in Queensland were primarily used to manage diabetesrelated foot disease, ${ }^{6}$ and the under-reporting in retrospective studies, ${ }^{12}$ our findings again seem plausible. Our 
Table 4 Independent associated factors for secondary admissions for foot-related conditions using multivariate logistical regression (ORs $(95 \% \mathrm{CI})$ )

\begin{tabular}{|c|c|c|c|c|}
\hline Risk factor & Unadjusted & p Value & Adjusted & p Value \\
\hline \multicolumn{5}{|l|}{ Model 1} \\
\hline Diabetes & 5.46 (2.33 to 12.78$)$ & $<0.001^{*}$ & 4.89 (2.07 to 11.57$)$ & $<0.001^{*}$ \\
\hline Current foot ulcer & 9.84 (4.13 to 23.45$)$ & $<0.001^{*}$ & $4.94(2.12$ to 16.67$)$ & $0.001^{*}$ \\
\hline Model 1 results: & $\begin{array}{l}\text { Pseudo } R^{2}: 0.233 \\
\text { Omnibus: } d f=2, p=<0.001\end{array}$ & $\begin{array}{l}\text { Missing: } 1(0.1 \%) \\
\text { H\&L: } p=0.755\end{array}$ & $\begin{array}{l}\text { Pseudo } R^{2}: 0.259 \\
\text { Omnibus: } d f=4, p=<0.001\end{array}$ & $\begin{array}{l}\text { Missing: } 5(0.7 \%) \\
\text { H\&L: } p=0.425\end{array}$ \\
\hline \multicolumn{5}{|l|}{ Model 2} \\
\hline Diabetes & 5.27 (2.23 to 12.45$)$ & $<0.001^{*}$ & No confounders identified & \\
\hline Foot risk status & & $<0.001^{*}$ & & \\
\hline Low risk & Referent & & & \\
\hline At risk & $2.19(0.56$ to 8.55$)$ & 0.258 & & \\
\hline High risk & $2.81(0.78$ to 10.18$)$ & 0.116 & & \\
\hline Acute & 16.12 (5.40 to 48.11$)$ & $<0.001^{\star}$ & & \\
\hline Model 2 results: & $\begin{array}{l}\text { Pseudo } R^{2}: 0.261 \\
\text { Omnibus: } d f=4, p=<0.001\end{array}$ & $\begin{array}{l}\text { Missing: } 2(0.3 \%) \\
H \& L: p=0.680\end{array}$ & & \\
\hline
\end{tabular}

findings also appear generalisable when interpreting diabetes rate trends between ours and other regions. The $23.5 \%$ inpatient diabetes prevalence found in our Queensland study is similar to the $24.7 \%$ reported in Victoria (Australia), ${ }^{17} 26.2 \%$ in the USA, ${ }^{49}{ }^{50}$ but higher than $15.8 \%$ in the UK. ${ }^{51}$ The diagnosed diabetes population prevalence in Queensland is $4.5 \%$ and $5.0 \%$ in Victoria $;{ }^{52}$ while the estimated national diabetes population prevalence for Australia is $7.8 \%, 9.2 \%$ in the USA and $4.9 \%$ in the UK. ${ }^{53}$ Also diabetes-related amputation rates, often used as a surrogate measure of the foot disease burden, showed similar trends with 15 per 100000 people reported in Queensland, ${ }^{6} 18$ in Australia, 36 in the USA and 9 in the UK. ${ }^{54}{ }^{55}$ These interpretations suggest our findings are plausible and potentially generalisable to other regions.

Our study also found that nearly all those primarily hospitalised for a foot-related condition were due to foot disease $(67 \%)$ or foot trauma (28\%). These findings were supported by our multivariate models reporting they were independantly associated with a foot disease disorder (critical PAD, foot infection or foot ulceration), foot trauma or had previous foot treatment from a GP or surgeon. These same independent associates have been consistently identified in diabetes inpatient populations; ${ }^{10} 113738$ however, our findings adjusted for diabetes in a representative inpatient population. Furthermore, after adjustment, inpatients classified with acute foot risk status were much more likely to be in hospital for the primary reason of a foot-related condition than those of lower foot risk status. This suggests, regardless of diabetes, that using a diabetes foot risk status system ${ }^{19}{ }^{32}$ may be useful to identify people highly likely to be admitted to hospital because of a foot-related condition.

In addition to those primarily hospitalised for a foot-related condition, $3.8 \%$ of participants reported a foot-related condition as a secondary reason for their admission. This meant the participant had been primarily admitted for another health condition, yet also required treatment in hospital to manage a foot-related condition. ${ }^{23}$ To the best of the authors' knowledge, no study has investigated the prevalence of secondary foot-related admissions. Participants with a secondary foot-related condition were more likely to have diabetes or a current foot ulcer. This is not surprising considering people with diabetes have very high rates of foot-related conditions compared with other disease processes in the population. ${ }^{15}{ }^{5}$ Furthermore, those with a current foot ulcer typically require frequent wound dressing changes ${ }^{42}$ within the average length of hospital admission. ${ }^{356}$ Overall, the primary and secondary reason for admission findings indicate that $11.2 \%$ of all inpatients need treatment for a foot-related condition during their hospitalisation.

The type of hospital and ward also appeared to impact on the prevalence of people admitted due to a foot-related condition. Our findings indicate major general hospitals have higher prevalences of people admitted with a foot-related condition than other hospital types. Those admitted with a foot-related condition as the primary reason were also more likely to be in a surgical ward, whereas those admitted as a secondary reason were mostly found in a medical ward. These findings may be explained by major general hospitals housing more of the necessary surgical disciplines needed to effectively manage complex foot-related conditions, ${ }^{9-12}$ 32-34 and thus more of these patients being transferred to these hospitals. Although this study has focused on inpatient explanations, the impact of available outpatient services cannot be discounted. ${ }^{6}$ This is especially the case considering recent significant reductions in diabetes-related foot disease admissions in 
Queensland were reportedly associated with improved outpatient multidisciplinary foot services. ${ }^{6}$

\section{Implications for policymakers, clinicians and researchers}

Our findings have significant potential implications for policymakers. To contextualise these finding, an 'average' 600-bed hospital could expect to manage 44 inpatients each night for the primary reason of a foot-related condition, including 29 for foot disease and 13 for foot trauma. This equates to an annual direct cost of \$A15.6 million for an average hospital if assuming \$A971 (2015) per Australian hospital bed day. ${ }^{56}$ Forecasting this across Australia's 49153 public hospital beds ${ }^{57}$ suggests Australia would need 3637 hospital beds each night, or 1.33 million beds each year, at an annual cost of $\$$ A1.29 billion to primarily manage foot-related conditions. Assuming a conservative 13-day average length of stay for foot-related conditions ${ }^{2-6}$ indicates Australia has over 102000 annual primary admissions for foot-related conditions, including 67600 for foot disease and 27600 for foot trauma. With cellulitis ranked as the 10th leading cause of Australian public hospital admissions with 35248 admissions, ${ }^{58}$ these figures would place foot-related conditions in the top 10 causes of hospital admission in Australia. Interestingly, two-thirds of these reported cellulitis admissions were infections in the lower leg and foot. ${ }^{58}$ These figures are likely to be conservative as they do not account for private hospitals, surgical procedures, secondary foot-related admissions and any other foot-related inpatient management.

These findings also suggest clinicians should focus their inpatient foot-related strategies on foot disease and foot trauma, regardless of diabetes. First, we recommend using a simple foot risk screening tool, ${ }^{19}{ }^{32}$ or foot ulcer visual inspection, as admission triage strategies to improve identification of inpatient foot-related conditions. Like recent amputation prediction tools,${ }^{10}$ these tools could also be enhanced by including critical PAD in the acute foot category to further improve identification. Second, our findings indicate those people hospitalised for a foot-related condition had not previously attended the recommended outpatient multidisciplinary foot team members. ${ }^{41132}$ Thus, we recommended all people with foot-related conditions have access to outpatient multidisciplinary foot teams, regardless of diabetes status. Third, our findings support other authors recommending episodes of foot-related hospitalisation should be an opportunity to triage inpatients into multidisciplinary foot teams for best practice care. ${ }^{22} 2859$ Last, it is suggested strategies already demonstrated to reduce the inpatient diabetic foot burden should be considered for all inpatients admitted for foot-related conditions, such as triaging foot-related admissions into specialist multidisciplinary foot wards. ${ }^{411} 2859$

Our findings also support further research. First, to confirm the findings of this study, we recommend implementing methodologically similar research in other regions. ${ }^{11} 59$ Second, our findings support recommendations that hospital discharge data coders are trained to more accurately identify and code foot-related condition admissions to enable more effective monitoring of standard hospital discharge data sets. ${ }^{12}$ Third, we recommend reporting the use of occupied hospital bed days, rather than whole admissions, to more specifically measure the burden of hospitalisation. Fourth, the foot disease and foot trauma factors identified in this study should be investigated for 'up stream' factors that may predict these foot-related hospitalisations. Last, it is recommended that clinical trials implementing strategies demonstrated to reduce the inpatient diabetic foot disease burden should be evaluated on all inpatients admitted for foot-related conditions.

\section{Strengths and weaknesses}

This study has several strengths. First, the study's findings are generalisable as we purposively investigated representative hospitals that reported very similar demographic, social determinant and medical history characteristics to those reported in other large inpatient studies. ${ }^{1758}$ Second, this study recruited total participant numbers $<3 \%$ of the original sample size calculated, reported a robust consent rate $>80 \%,{ }^{18}$ and no differences in demographic characteristics between consenting and non-consenting inpatients. Third, the study used a data collection instrument modified from a very similar valid and reliable data collection instrument that captured a range of standard self-reported or clinically diagnosed foot-related variables. ${ }^{19}$ Fourth, data collectors had previous similar data collection experience, further specific training and reported high accuracy and validity when tested against simulated cases and medical records. Last, the multivariate models used in this study were recommended to identify independent associated factors after adjusting for identified confounders and the sample size was large enough to account for over 50 variables. $^{42} 43$

This study also had a number of limitations. First, the study was cross-sectional and can only report on associated factors and not causal relationships. ${ }^{41}$ Second, as a point-prevalence study, it relies on the day of data collection being representative of standard inpatient activity. ${ }^{18}$ Third, while excluding cognitively impaired patients is standard, ${ }^{15-18}$ this may have introduced a selection bias towards under-reporting foot-related conditions as excluded patients were mostly older cognitively impaired patients that have higher foot disease rates than cognitively intact patients. ${ }^{60}$ Fourth, although standard self-reported medical history and clinically diagnosed foot-related variables were used, these were not gold standard biomedical criteria and may underreport medical conditions. ${ }^{10} 17{ }^{34}$ Fifth, while the study used a data collection instrument modified from an existing valid and reliable instrument, it was only retested against simulated cases and medical records, which limits our knowledge on its validity and reliability 
for capturing these data. ${ }^{41}$ Last, as this study used over 100 statistical tests, there is the likelihood of a type 1 statistical error. $^{41-43}$

\section{CONCLUSIONS}

This is the first study to investigate the burden caused by people admitted to hospital because of foot-related conditions within a representative inpatient population. Findings indicate the burden is significantly higher than previously reported with 1 in every 13 inpatients in hospital for the primary reason of a foot-related condition. These patients were mostly affected by foot disease or foot trauma, in major general hospitals and most did not have diabetes. It is recommended that serious consideration be given to future strategies to investigate and intervene in this considerable, yet historically underappreciated, inpatient burden.

\section{Author affiliations}

${ }^{1}$ School of Clinical Sciences, Queensland University of Technology, Brisbane, Queensland, Australia

${ }^{2}$ Institute of Health and Biomedical Innovation, Queensland University of Technology, Brisbane, Queensland, Australia

${ }^{3}$ Allied Health Research Collaborative, Metro North Hospital \& Health Service, Brisbane, Queensland, Australia

${ }^{4}$ Department of Podiatry, Metro North Hospital \& Health Service, Queensland Health, Brisbane, Queensland, Australia

${ }^{5}$ Wound Management Innovation Cooperative Research Centre, Brisbane, Queensland, Australia

${ }^{6}$ School of Physiotherapy, Australian Catholic University, Banyo, Queensland, Australia

${ }^{7}$ Department of Podiatry, North West Hospital \& Health Service, Mount Isa, Queensland, Australia

${ }^{8}$ Department of Podiatry, West Moreton Hospital \& Health Service,

Queensland Health, Ipswich, Queensland, Australia

${ }^{9}$ Department of Endocrinology and Diabetes, Royal Brisbane and Women's Hospital, Brisbane, Queensland, Australia

${ }^{10}$ School of Medicine, The University of Queensland, Brisbane, Queensland, Australia

Acknowledgements The authors wish to warmly acknowledge the tireless work of the multiple data collectors from Queensland Health and Queensland University of Technology. Without their enthusiasm this study would not have been possible. The authors also wish to recognise the ongoing support provided to this work by Queensland Health, Wound Management Innovation Cooperative Research Centre, the Australian Government's Cooperative Research Centres Program and Queensland University of Technology.

Contributors PAL conceived, designed, collected data, analysed data, wrote and reviewed/edited the manuscript. SEH, SSK, MCK and LR conceived, designed, collected data and reviewed/edited the manuscript. VN, CT, SJ, EMK, MCdE designed, collected data and reviewed/edited the manuscript.

Funding This work was supported by grant funding from Queensland Health (Queensland Government, Australia) and the Wound Management Innovation Cooperative Research Centre (Australia).

Competing interests None declared.

Ethics approval This study received ethical approval from two Human Research Ethics Committee (HREC): The Prince Charles Hospital HREC (Ethics No. HREC/13/QPCH/5) and the Queensland University of Technology HREC (Ethics No. 1300000367).

Provenance and peer review Not commissioned; externally peer reviewed.

Data sharing statement No additional data are available.
Open Access This is an Open Access article distributed in accordance with the Creative Commons Attribution Non Commercial (CC BY-NC 4.0) license, which permits others to distribute, remix, adapt, build upon this work noncommercially, and license their derivative works on different terms, provided the original work is properly cited and the use is non-commercial. See: http:// creativecommons.org/licenses/by-nc/4.0/

\section{REFERENCES}

1. Lazzarini PA, Hurn SE, Fernando ME, et al. Prevalence of foot disease and risk factors in general inpatient populations: a systematic review and meta-analysis. BMJ Open 2015;5:e008544.

2. Lazzarini PA, Hurn SE, Kuys SS, et al. Foot-related conditions in hospitalised populations: a literature review. Wound Pract Res 2016;24:16-35.

3. Lazzarini PA, Gurr JM, Rogers JR, et al. Diabetes foot disease: the Cinderella of Australian diabetes management? J Foot Ankle Res 2012;5:24-24

4. Boulton AJM, Vileikyte L, Ragnarson-Tennvall G, et al. The global burden of diabetic foot disease. Lancet 2005;366:1719-24.

5. Currie CJ, Morgan CL, Peters JR. The epidemiology and cost of inpatient care for peripheral vascular disease, infection, neuropathy, and ulceration in diabetes. Diabetes Care 1998;21:42-8.

6. Lazzarini PA, O'Rourke SR, Russell AW, et al. Reduced incidence of foot-related hospitalisation and amputation amongst persons with diabetes in Queensland, Australia. PLOS ONE 2015;10:e0130609.

7. Reed JF III. An audit of lower extremity complications in octogenarian patients with diabetes mellitus. Int J Low Extrem Wounds 2004;3:161-4.

8. Bosse MJ, McCarthy ML, Jones AL, et al. The insensate foot following severe lower extremity trauma: an indication for amputation? J Bone Joint Surg Am 2005;87:2601-8.

9. Ly TV, Travison TG, Castillo RC, et al. Ability of lower-extremity injury severity scores to predict functional outcome after limb salvage. J Bone Joint Surg Am 2008;90:1738-43.

10. Mills JL Sr, Conte MS, Armstrong DG, et al. The Society for Vascular Surgery Lower Extremity Threatened Limb Classification System: risk stratification based on wound, ischemia, and foot infection (WIfl). J Vasc Surg 2014;59:220-34.e1-2.

11. Prompers L. Diabetic foot disease in European perspective: results from the Eurodiale study. [PhD Thesis]. Maastricht University. 2008. http://digitalarchive.maastrichtuniversity.nl/fedora/get/guid:33a72da3d773-4f20-9873-c6321b89b99a/ASSET1. (accessed 28 Aug 2015).

12. Wraight PR, Lawrence SM, Campbell DA, et al. Retrospective data for diabetic foot complications: only the tip of the iceberg? Intern Med J 2006;36:197-9.

13. Murray CJL, Ezzati M, Flaxman AD, et al. GBD 2010: design, definitions, and metrics. Lancet 2012;380:2063-6.

14. National Health Peformance Authority. MyHospitals Find hospitals. Sydney, Australia: National Health Performance Authority, 2015. http://www.myhospitals.gov.au/. (accessed 28 Aug 2015)

15. Gottrup F, Henneberg E, Trangbaek R, et al. Point prevalence of wounds and cost impact in the acute and community setting in Denmark. J Wound Care 2013;22:413-20.

16. Gunningberg L, Stotts NA. Tracking quality over time: what do pressure ulcer data show? Int J Qual Health Care 2008;20:246-53.

17. Bach LA, Ekinci El, Engler D, et al. The high burden of inpatient diabetes mellitus: the Melbourne Public Hospitals Diabetes Inpatient Audit. Med J Aust 2014;201:334-8.

18. Woodbury MG, Houghton PE. Prevalence of pressure ulcers in Canadian healthcare settings. Ostomy Wound Manage 2004;50:22-8.

19. Lazzarini PA, Ng V, Kinnear EM, et al. The Queensland high risk foot form (QHRFF) - is it a reliable and valid clinical research tool for foot disease? J Foot Ankle Res 2014;7:7-7.

20. Earl BJ, Lazzarini PA, Kinnear EM, et al. Prevalence of active foot disease and foot disease risk factors in a subacute inpatient rehabilitation facility: a cross-sectional prevalence study. J Foot Ankle Res 2014;7:41-41.

21. Crawford F, Anandan C, Chappell FM, et al. Protocol for a systematic review and individual patient data meta-analysis of prognostic factors of foot ulceration in people with diabetes: the international research collaboration for the prediction of diabetic foot ulcerations (PODUS). BMC Med Res Methodol 2013;13:22-22.

22. Wallymahmed ME, Dawes S, Clarke G, et al. Hospital in-patients with diabetes: increasing prevalence and management problems. Diabet Med 2005;22:107-9.

23. Health Statistics Branch. Queensland Hospital Admitted Patient Data Collection (QHAPDC): manual of instructions and procedures for the reporting of QHAPDC data. Brisbane: Queensland Health, 2013. 
http://www.health.qld.gov.au/hsu/default.asp. (accessed 28 Aug 2015).

24. Grant JF, Chittleborough CR, Taylor AW, et al. The North West Adelaide Health Study: detailed methods and baseline segmentation of a cohort for selected chronic diseases. Epidemiol Perspect Innov 2006;3:4-4.

25. Australian Bureau of Statistics (ABS). Information paper: an introduction to socio-economic indexes for areas (ABS Cat. No. 2039.0). Canberra: ABS, 2006. http://www.abs.gov.au/ausstats/ abs@.nsf/mf/2039.0/. (accessed 28 Aug 2015).

26. Australian Bureau of Statistics (ABS). Australian Standard Geographical Classification (ABS Cat No. 1216.0). Canberra: ABS, 2011. http://www.abs.gov.au/ausstats/abs@.nsf/mf/1216.0. (accessed 28 Aug 2015).

27. Burton NW, Haynes M, Wilson L-AM, et al. HABITAT: A longitudinal multilevel study of physical activity change in mid-aged adults. $B M C$ Public Health 2009;9:76-76.

28. Wraight PR, Lawrence SM, Campbell DA, et al. Creation of a multidisciplinary, evidence based, clinical guideline for the assessment, investigation and management of acute diabetes related foot complications. Diabet Med 2005;22:127-36.

29. Abbott CA, Carrington AL, Ashe $\mathrm{H}$, et al. The North-West Diabetes Foot Care Study: incidence of, and risk factors for, new diabetic foot ulceration in a community-based patient cohort. Diabet Med 2002;19:377-84.

30. Barton CJ, Bonanno D, Menz HB. Development and evaluation of a tool for the assessment of footwear characteristics. J Foot Ankle Res 2009;2:10-10.

31. Menz HB, Gill TK, Taylor AW, et al. Predictors of podiatry utilisation in Australia: the North West Adelaide Health Study. J Foot Ankle Res 2008:1:8-8.

32. National Health \& Medical Research Council (NHMRC) Guidelines. National evidence-based guideline on prevention, identification and management of foot complications in diabetes (part of the quidelines on management of type 2 diabetes). Melbourne: Baker IDI Heart \& Diabetes Institute, 2011. https://www.nhmrc.gov.au/ guidelines-publications/di21. (accessed 28 Aug 2015).

33. Schaper NC. Diabetic foot ulcer classification system for research purposes: a progress report on criteria for including patients in research studies. Diabetes Metab Res Rev 2004;20(Suppl 1): S90-S5.

34. Hirsch AT, Haskal ZJ, Hertzer NR, et al. ACC/AHA 2005 Practice Guidelines for the management of patients with peripheral arterial disease (lower extremity, renal, mesenteric, and abdominal aortic). Circulation 2006;113:e463-654.

35. Schaper NC, Andros G, Apelqvist J, et al. Diagnosis and treatment of peripheral arterial disease in diabetic patients with a foot ulcer. A progress report of the International Working Group on the Diabetic Foot. Diabetes Metab Res Rev 2012;28(Suppl 1):218-24.

36. Apelqvist J, Elgzyri T, Larsson $\mathrm{J}$, et al. Factors related to outcome of neuroischemic/ischemic foot ulcer in diabetic patients. $J$ Vasc Surg 2011;53:1582-8.

37. Armstrong DG, Lavery LA, Harkless LB. Validation of a diabetic wound classification system. The contribution of depth, infection, and ischemia to risk of amputation. Diabetes Care 1998;21:855-9.

38. Lavery LA, Armstrong DG, Murdoch DP, et al. Validation of the Infectious Diseases Society of America's diabetic foot infection classification system. Clin Infect Dis 2007;44:562-5.

39. Lipsky BA, Berendt AR, Cornia PB, et al. Executive summary: 2012 Infectious Diseases Society of America clinical practice guideline for the diagnosis and treatment of diabetic foot infections. Clin Infect Dis 2012;54:1679-84.
40. Agresti A, Coull B. Approximate is better than "exact" for interval estimation of binomial proportions. Am Stat 1998;52:119-26.

41. Portney LG, Watkins MP. Foundations of clinical research applications to practice. 3rd edn. New Jersey, USA: Pearson Prentice, 2009.

42. Tabachnick BG, Fidell LS. Using multivariate statistics. 5th edn. Boston, USA: Allyn and Bacon, 2007.

43. Hosmer D, Lemeshow S. Applied logistic regression. 2nd edn. New York, USA: John Wiley \& Sons, 2000.

44. Baba M, Davis WA, Norman PE, et al. Temporal changes in the prevalence and associates of diabetes-related lower extremity amputations in patients with type 2 diabetes: The Fremantle Diabetes Study. Cardiovasc Diabetol 2015;14:152.

45. Holman N, Young B, Stephens $\mathrm{H}$, et al. Pilot study to assess measures to be used in the prospective audit of the management of foot ulcers in people with diabetes. Diabet Med 2015;32:78-84.

46. Ndip A, Rutter MK, Vileikyte L, et al. Dialysis treatment is an independent risk factor for foot ulceration in patients with diabetes and stage 4 or 5 chronic kidney disease. Diabetes Care 2010;33:1811-16

47. Landis JR, Koch GG. An application of hierarchical kappa-type statistics in the assessment of majority agreement among multiple observers. Biometrics 1977;33:363-74.

48. Landis JR, Koch GG. The measurement of observer agreement for categorical data. Biometrics 1977;33:159-74.

49. Umpierrez GE, Isaacs SD, Bazargan N, et al. Hyperglycemia: an independent marker of in-hospital mortality in patients with undiagnosed diabetes. J Clin Endocrinol Metab 2002;87:978-82.

50. American Diabetes Association. Economic costs of diabetes in the U.S. in 2012. Diabetes Care 2013;36:1033-46.

51. National Health Service. National Diabetes Inpatient Audit 2013. Leeds, UK: Health \& Social Care Information Centre, 2014. http://www.hscic. gov.uk/searchcatalogue?productid=14305. (accessed 15 Apr 2016).

52. National Diabetes Services Scheme. Australian diabetes map. Canberra, Australia: Diabetes Australia, 2015. https://www.ndss. com.au/diabetes-map. (accessed 15 Apr 2016).

53. International Diabetes Federation (IDF). IDF Diabetes Atlas. 6th edn Brussels, Belgium: IDF, 2013. https://www.ndss.com.au/ diabetes-map (accessed 15 Apr 2016)

54. Bureau of Health Information. Healthcare in focus: how NSW compares internationally. Sydney, Australia: NSW Government 2010. http://www.bhi.nsw.gov.au/. (accessed 15 Apr 2016).

55. Squires DA. The U.S. health system in perspective: a comparison of twelve industrialized nations. Issue Brief (Commonwealth Fund) 2011;16:1-14.

56. Graves N, Halton K, Doidge S, et al. Who bears the cost of healthcare-acquired surgical site infection? J Hosp Infect 2008;69:274-82.

57. Australian Institute of Health \& Welfare (AIHW). Hospital resources 2013-2014: Australian hospital statistics. Canberra, Australia: AlHW, 2015. http://www.aihw.gov.au/publication-detail/?id=60129551442. (accessed 28 Aug 2015).

58. Australian Institute of Health \& Welfare (AlHW). Australian hospital statistics 2011-12. Canberra: AlHW, 2013. http://www.aihw.gov.au/ publication-detail/?id=60129543133. (accessed 28 Aug 2015).

59. Rayman G, Taylor CG, Malik R, et al. The national inpatient diabetes audit reveals poor levels of inpatient foot care. Diabetologia 2010;53: S406.

60. Canadian Institute for Health Information. Compromised wounds in Canada. Ottawa, Canada: Canadian Institute for Health Information, 2013. https://secure.cihi.ca/estore/productFamily.htm? locale=en\&pf=PFC2320\&lang=en. (accessed 28 Aug 2015). 